\title{
Learning Analytics and Formative Assessment to Provide Immediate Detailed Feedback Using a Student Centered Mobile Dashboard
}

\author{
Naif Radi Aljohani* \\ Faculty of Computing and Information Technology \\ King Abdulaziz University, Jeddah-Saudi Arabia \\ nraljohani@kau.edu.sa
}

\author{
Hugh C. Davis \\ * School of Electronics and Computer Science \\ University of Southampton, UK \\ hcd@ecs.soton.ac.uk
}

\begin{abstract}
The 'immediacy' of feedback on academic performance is a common characteristic shared by both Learning Analytics (LA) and Formative Assessment (FA), and such immediacy could be facilitated by supporting the mobility of learners. However, there is little literature that investigates the significance of combining these two techniques. Therefore, this paper will discuss the analytical application called Quiz My Class Understanding (QMCU) which was purposely developed to investigate the significance of the combination between LA and FA techniques in order to provide students with immediate detailed feedback. Furthermore, it reports on a case study which reflects the role QMCU students' centered mobile dashboard in increasing the students' engagement with the QMCU dashboard.
\end{abstract}

Keywords-Learning Analytics; Mobile Learning Analytics Formative Assessment; Mobile Formative Assessment; Immediate Feedback

\section{INTRODUCTION AND MOTIVATIONS}

The growing interest in Learning Analytics (LA) has emerged as a result of the increasing complexity and sophistication of higher-education research, practice and policy in recent years. Essentially, higher education might be about students constructing their own knowledge independently. While students are considered to be responsible for building knowledge, learning is also understood to depend on institutions and staff providing learning and environmental conditions that stimulate, encourage and value student involvement and participation [1]. Based on this view, students are seen as knowledge consumers, whereas the university and staff are the suppliers who can encourage the students to learn and who potentially provide the best possible environmental support to help students consume and get involved in order to understand the required knowledge.

With the wide utilisation of communication technologies in learning, the amount of data about students and their learning activities is accumulating at a rapid pace. Consequently, this utilisation of technologies has played an important role in opening new windows of opportunity to use this available data to uncover educational problems in their early stages using Learning analytics (LA) techniques.
LA has been utilised to investigate the possibility of analytics to improve the learning for students. LA has been defined as "the measurement, collection, analysis and reporting of data about learners and their contexts, for purposes of understanding and optimising learning and the environments in which it occurs"[2]. It has been considered that, 'the larger promise of learning analytics, however, is that when correctly applied and interpreted, it will enable faculty to more precisely identify student learning needs and tailor instruction appropriately' [3].

LA focuses principally on data analysis at the level of the learning process $[4,5]$. Information on all of students, teachers, and learning materials may be considered. Therefore, LA can be used to measure the quality of learning process. When it comes to the quality of the learning process, Formative Assessment (FA) is another useful way to provide both teachers and students with helpful information on performance on an on-going basis.

One important question is: Why should LA and FA be used together? The first reason is that both methods provide immediate feedback. The second (and very important reason) is that LA yields detailed feedback and not only increases the awareness of individual students about the quality of a particular piece of work but also their awareness of the quality of their other work. According to [6] "assessment alone changes very little; likewise, learning analytics cannot act alone in radically disrupting and transforming education. Assessment (when done well) is about the authentic and deep understanding and improvement of teaching and learning. Analytics is about using the power of information technology to see patterns of success (or failure) in learning. Combining the two might actually produce the seeds of transformation - a powerful inquiry into what supports authentic, deep, transformative learning for students'.

Most LA applications use a dashboard to show the results of analysis. Several dashboards have been developed in order to deliver, report and visualize the feedback so that it is seen by the intended users, such as mangers, teachers or students. These include, for example: Teacher ADVisor [7], LOCO-Analyst [8], Moodle Dashboard [9]. However, most of these dashboards 
are intended to be used by teachers [10]. Further, they were not specifically developed for use with mobile devices.

There are many examples that showed how mobile devices can support and facilitate the FA and the delivery of immediate feedback $[11,12]$. However, most do not provide detailed feedback. In other words, they give individual results as simple numbers which do not allow learners to compare their results with those of peers. Thus, individual academic performance cannot be compared with overall class performance. Further, they are platform dependent, meaning that they do not work on all mobile devices. This limitation required students to have a specific type of mobile device to benefit from the provided mobile applications which can be difficult to achieve.

Even in the mobile age, LA research has barely addressed the importance of supporting learner mobility. The nascent field of Mobile Learning Analytics (MLA) has been defined: 'MLA focuses mainly on the collection, analysis and reporting of the data of mobile learners, which can be collected from the mobile interactions between learners, mobile devices and available learning materials; it might also be supported by the preregistered data about learners in different university systems'[13]. This paper discusses the QMCU analytical application which is intended to be used by students to provide them with 'Student's Centred Dashboard' that can be accessed using any mobile device. The focus here is on the ability of the customized mobile interface to deliver detailed feedback created by both LA and FA.

This paper is organized as follows: Section II briefly talks about the FA and the conditions of FA that are considered in QMCU. Section III presents the quiz model of QMCU analytical application. Section IV theoretically explains the QMCU and how it combines LA and FA to provide students with an immediate detailed feedback. Section V highlights the main features of students mobile dashboard of QMCU. Section VI clarifies how QMCU is used and section VII describes the case study. Section VIII reports the results of the case study. Section IX discuss the finding of the case study. Finally Section $\mathrm{X}$ concludes the paper.

\section{THEORETICAL BACKGROUND}

\section{A. Formative assessment}

Research reveals several different definitions for the FA. For instance, it is defined as 'a systematic process to continuously gather evidence about learning' [14] . It is also defined by Sadler [15] as 'Formative assessment is concerned with how judgments about the quality of student responses (performances, pieces, or works) can be used to shape and improve the student's competence by short-circuiting the randomness and inefficiency of trial-and-error learning'.

After students perform a particular task, it can be useful for them to receive knowledge about how well it was completed. Negative feedback can help assist students in becoming conscious of their mistakes and help them learn how to perform better. However, feedback can also highlight positive attributes, and in this sense can provide encouragement and motivation to the students. Therefore, well-balanced feedback can provide guidance and stimulation to an individual through maintaining or modifying actions relevant to the completion of a task [16]. The feedback of FA helps students to be active participants and aware of their academic progress in early stages of the course. Also, it informs teachers about their teaching effectiveness and to what degree their students have mastered the given learning materials [17].

\section{B. Conditions of effective formative assessment}

There are many efforts to identify the conditions of effective FA, such as the eight conditions suggested by [18]; however, those are derived from school-based research. For the purpose of this research, we consider three conditions out of the ten conditions suggested by [19], as they are meant for a higher education environment, which is the focus of our research.

These conditions are : 'A) Sufficient feedback is provided, both often enough and in enough detail, B) The feedback focuses on students' performance, on their learning and on actions under the students' control, rather than on the students themselves and on their characteristics, C) The feedback is timely in that it is received by students while it still matters to them and in time for them to pay attention to further learning or receive further assistance'[19]. Another reason behind choosing these three conditions is their direct relationship with immediacy of feedback.

\section{QMCU QUIZ MODEL}

To satisfy these three conditions for useful feedback, we specify three compulsory characteristics that each question of each quiz has to have in the quiz model . These characteristics are as follows:

\section{A. Learning objectives}

Each question has to cover the specific learning objective of each class. Each learning objective can be covered by many questions; in other words, each learning objective is converted to the form of one question or questions [11].

The conversion of learning objectives to questions might help lecturers determine the learning objectives that students have mastered. Thus, it might also help lecturers to self-evaluate the effectiveness of their teaching outcomes. Furthermore, it might guide the students to the main learning objectives of the given class, which is turn might help them to evaluate their understanding.

\section{B. Difficulty level of question}

Each question has to be categorized to have one difficulty level, whether hard, medium or easy. For lecturers, assigning the difficulty level to each question might provide them with useful insight into the abilities of their students and the level of their understanding. Thus, the lecturer might be able to customize the learning materials in such a way that helps students to follow them. In addition, assigning a difficulty level to each question might help students evaluate the level of their understanding, meaning that it might help them find out if they understand the given class in such a way that they are not only able to answer easy questions but also that they are able to answer more advanced complex questions. 


\section{Bloom's taxonomy}

Each question is assigned to one of Bloom's Taxonomy elements. Assigning them the Bloom's Taxonomy might help lecturers to further find out the level of the students' cognitive understanding; also, it might be a good indicator of their teaching style. In this research, the new version of Bloom's Taxonomy (Remembering, Understanding, Applying, Analysing, Evaluating, and Creating) was adopted, as we found it easier for students to understand [20].

\section{Quiz My Class Understanding (QMCU)}

For our investigation, we built a mobile web application that could be used across platforms using HTML5, jQuery Mobile, and ASP MVC4; we thus sought to overcome the problem of platform dependency. The QMCU dashboard has two interfaces; these are a customized mobile dashboard which can be accessed from any mobile device as well as a regular dashboard accessible from a regular computer. Therefore, students are not forced to use a specific device (mobile and regular computers) to access the QMCU system; rather, they could choose whatever they want based on their preferences.

QMCU was built to combine the benefits of FA and LA techniques. QMCU follows the FA techniques in order to allow students to test their knowledge and to provide them with timely, immediate feedback. LA techniques helps QMCU to provide students with detailed feedback not limited to their individual results represented as numbers, but that is rather much broader. The feedback provided by QMCU is meant to help the students become aware of their individual performance, their performance compared with their peers and the class performance as a whole. For these reasons, we have labelled the feedback as 'detailed'.

\section{QMCU STUDENT MOBILE DASHBOARD MAIN FEATURES}

The QMCU mobile dashboard provides students with a great deal of necessary academic knowledge. For the purposes of this paper, we will consider some of its main features, which are as follows:

\section{A. Your Class's Overall Result}

This feature allows students to see how the class performed in a particular quiz. The benefit here is that it allows student to compare his/her overall result with the class's overall result. Basically, the feature was added to increase the students' awareness about their performance compared with the class performance.

\section{B. Performance Based on Difficulty Level of question}

As mentioned in our suggested quiz model, each question has to have a difficulty level. This helps in providing students with feedback that might assist them to measure the level of their understanding based on the difficulty of question. In other words, we want to show the students if their understanding of the information given in the class helps them to answer only the easy, medium, difficult questions or all of them. More importantly, each student is able to determine his/her performance based on the difficulty level of questions compared with the class performance based on the difficulty level of questions. Thus, this might motivate them to work harder and to pay more attention during lectures (Figure 1).

\section{Performance Based on Bloom's Taxonomy}

This feature is meant to enable students to discover their level of cognitive understanding in each class. Students can compare their performance based on Bloom's Taxonomy with the class's performance, also based on each layer of Bloom's Taxonomy (Figure 1).
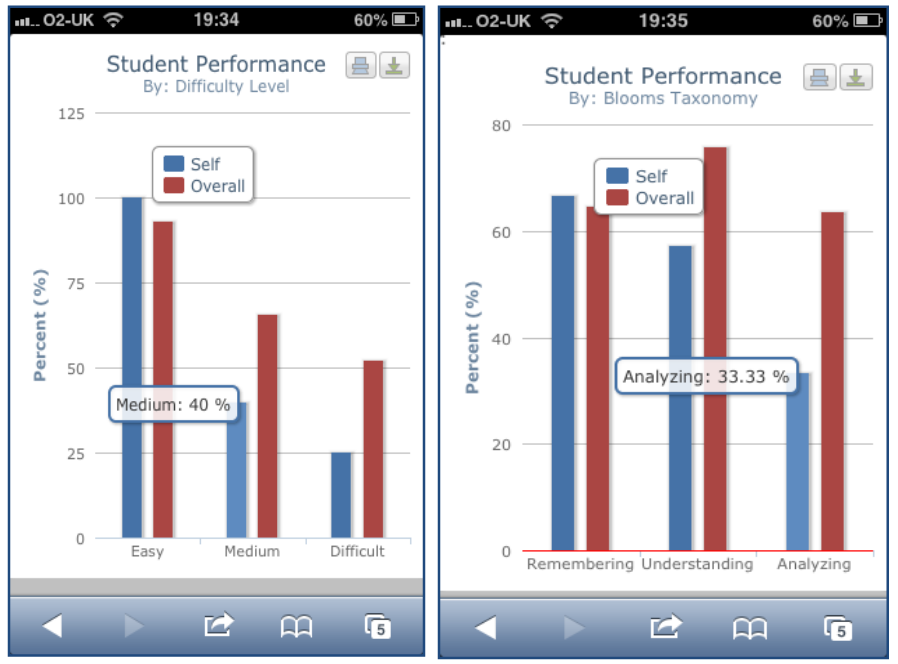

Figure 1:Screenshot from QMCU student's mobile dashboard

\section{Performance based on today's session Learning Objectives}

Students might attend a lecture and fail to pick up the most important information. In big classes, it might be difficult both for students and lecturers to communicate with each other, which in turn might prevent students from asking for further clarification. When it comes to the university environment, students usually are encouraged to be independent learners. The main objective of this feature is to guide students to the main learning objectives of each class. In addition, the comparison based on the learning objectives of a given class might help students to know which learning objectives they do not understand, which might in turn also allow them to focus their efforts when they review their result.

\section{E. Your historical performance based on quiz}

This feature was added to show students their progress based on the result of each quiz compared with the class performance. This to allow students to easily monitor their progress of their performance over the time.

\section{HOW QMCU IS USED}

In this research we follow the strategy of giving students a weekly quiz. First of all, lecturers prepare the questions for each quiz, following the quiz model mentioned in section III. The quiz will be available right after the weekly lecture, for eight hours. The time limitation was purposely added here, as the aim is to allow the students to quiz their understanding of the lecture that they have just attended. This might also encourage them to attend the lecture and focus more in order to perform well in the quiz. So here, we do not want to force students to attend the 
lecture, but we provide them with a tool that might encourage them to be active participants in the course.

Once students submit their result, they will be provided with immediate feedback that they can see by accessing their personal dashboard provided by QMCU. It is important to mention that students will not be able to review their answers to questions to see their mistakes and compare them with the right answers before the eight hours has elapsed. This was done to increase the completion rate by students and to avoid their sharing the right answers. Also, it was to encourage students to access the QMCU dashboard to see what others did

\section{CASE STUDY}

\section{A. The context of study and the Participants}

This study was conducted at a university in Saudi Arabia. A particular course was chosen for study and assigned the pseudonym"COMP000" to protect the privacy of students and lecturers (certain results were shown as figures). A total of 72 students participated voluntarily. All could access the application using mobile and non-mobile devices.

\section{B. The Procedure and the instruments}

The steps outlined in section VI were followed. To investigate the usefulness of the customized mobile interface of QMCU, students were given the freedom to choose the interface (mobile and non-mobile) they wanted to use based on their circumstances in order to allow the students to experience both analytical dashboards (mobile and regular computers). This freedom of device choice should allow students to form views on the utility of both interfaces. The aim here is to let the students decide which interfaces they liked more and why instead of forcing them to use specific interface.

At the end of the case study, we distributed questionnaires to the participants, and 51 out of 72 students answered the questionnaire. Observation was also used in this study.

\section{THE STUDY FINDINGS}

\section{A. Access to the QMCU Dashboard}

In the questionnaire, students were asked how they accessed to the QMCU dashboard. According to their answers, we found that 14 students accessed the dashboard using a non-mobile device, 20 used a mobile device and, based on their circumstances, 17 used both a mobile and a non-mobile device.

\section{B. Preferred way of accessing to the QMCU dashboard}

Following the above question students were asked to choose which device they preferred to use in order to understand which way of access they preferred. We found that $70 \%$ of students preferred to use the customized mobile dashboard more than the customized non-mobile dashboard of QMCU.

\section{Relationship between the preferred way of accessing to the QMCU dashboard and the device students used}

To test the independence of the assumption that the type of device students used and the device they preferred to use were the same, we ran the $\mathrm{X}^{2}$ test of independence. The evidence suggested that the independent assumption should be rejected $\left[\mathrm{X}^{2}(2)=18.818\right.$, p-value $\left.<0.001\right]$. As one cell had a zero frequency, the p-value was calculated using a Monte Carlo method with 10,000 simulations [21]. We found that a relationship existed between the type of device used and the type of device preferred (Table 1).

TABLE 1:ACESS TO THE DASHBAORD AND THE PREFERRED DEVICE TO USE, CROSSTABULATION

\begin{tabular}{|c|l|l|l|l|}
\hline \multicolumn{2}{|c|}{} & \multicolumn{2}{l|}{$\begin{array}{l}\text { Which device did you } \\
\text { prefer to use }\end{array}$} & Total \\
\cline { 3 - 5 } & non-mobile & Mobile & \\
\hline \multirow{2}{*}{$\begin{array}{c}\text { Access to the } \\
\text { QMCU } \\
\text { dashboard }\end{array}$} & non-mobile & 9 & 5 & 14 \\
\cline { 2 - 5 } & Mobile & 0 & 20 & 20 \\
\cline { 2 - 5 } & Both & 6 & 11 & 17 \\
\hline Total & 15 & 36 & 51 \\
\hline
\end{tabular}

\section{The role of customized mobile centered dashbaord}

To further understand the utility of the customized mobile dashboard, we erected three research hypotheses (below). We used $\mathrm{H}_{0}$ to refer to the null hypotheses and $\mathrm{H}_{1}$ to the alternate. These hypotheses were posed as questions to the students, who could either agree or disagree. We calculated the percentages of mobile students who agreed/disagreed.

$\mathrm{H}_{0}$ : The version of QMCU was not useful.

$\mathrm{H}_{\mathrm{a}}$ : The mobile version of QMCU was useful.

$\mathrm{H}_{0}$ : The mobile version of QMCU does not help me to do the quiz anytime anywhere.

$\mathrm{H}_{\mathrm{a}}$ : The mobile version of QMCU helps me to do the quiz anytime anywhere.

$\mathrm{H}_{0}$ : The mobile dashboard of QMCU does not help me to discuss my result with others anytime anywhere.

$\mathrm{H}_{\mathrm{a}}$ : The mobile dashboard of QMCU helps me to discuss my result with others anytime anywhere.

The sample has only two possible values, agreement (success) and disagreement (failure). The sample fails most parametric assumptions such as presence of a normal distribution; a non-parametric test (a binomial test) was therefore used to establish how significantly success and failure differed from the median. We calculated the numbers and percentages of agreement and examined whether these percentage were significantly higher than the midpoint $50 \%$ using the binomial test [21]. The formula yielding the $95 \%$ confidence interval in such circumstances is:

$$
C I=p \pm 1.96 \sqrt{\frac{p(1-p)}{n}}
$$

Where $p$ is the percentage and $n$ the sample size, the value 1.96 is derived from the standard normal distribution and renders the confidence interval $95 \%$.

For the first hypothesis, most students (84\%) agreed that the customized mobile dashboard was useful; we are therefore $95 \%$ confident that the true proportion preferring the mobile version lies between $74.3 \%$ and $94.3 \%$. This is significantly higher than 
$50 \%$ (which is what would be expected if the mobile and nonmobile versions were of equal utility) based on the binomial test (p-value $<0.001)$.

For the second hypothesis, $88 \%$ of students agreed that the customized mobile interface helped them to do the quiz anytime anywhere. Therefore, we are $95 \%$ confident that the true proportion that would agree with that statement lies between $79.4 \%$ and $97.1 \%$ (p-value $<0.001$ ). Thus, the mobile version indeed allowed students to take the quiz anytime anywhere.

Finally, for the third research hypothesis, $80 \%$ of students thought that the mobile dashboard helped them discuss their results with others on the move. This means that the true proportion lies between $67.1 \%$ and $89.7 \%$, thus again significantly higher than $50 \%$ (p-value $<0.001$ ). The mobile dashboard indeed allowed students to engage more with QMCU and allowed them to talk about results anytime anywhere (Table 2).

TABLE 2:BINOMIAL TEST

\begin{tabular}{|l|l|l|l|l|l|}
\hline Hypotheses & Groups & Category & $\mathbf{N}$ & $\begin{array}{l}\text { Observed } \\
\text { proportion }\end{array}$ & $\begin{array}{l}\text { Exact } \\
\text { Sig. }\end{array}$ \\
\hline Hypothesis 1 & Group1 & Agree & 43 & .84 & .000 \\
& Group2 & Disagree & 8 & .16 & \\
\hline Hypothesis 2 & Group1 & Agree & 45 & .88 & .000 \\
& Group2 & Disagree & 6 & .12 & \\
\hline Hypothesis 3 & Group1 & Agree & 41 & .80 & .000 \\
& Group2 & Disagree & 10 & .20 & \\
\hline
\end{tabular}

\section{DISCUSSION}

QMCU was developed to provide students with a personal dashboard that could increase their awareness of study progress. In today's world of 'independent learning', students need such a tool to allow them to be better learners and not to always be under scrutiny by the university. To more personalize the 'Student's Centred Dashboard' of QMCU, we provided the students with the mobile customized dashboard.

In this research, the customized mobile dashboard can be considered a 'success factor' for the following reasons:

- Of all students, $70 \%$ preferred to use the mobile dashboard, and, indeed, 20 students used it exclusively. Further, 5 of 14 students who sometimes accessed the dashboard using a non-mobile dashboard preferred to use the mobile dashboard. Most importantly, 11 students out of 17 who, depending on their circumstances, used both interfaces preferred to use the mobile interface. Thus, the mobile dashboard motivated students to use the QMCU more.

- Use of a mobile customized interface allowed students to access the dashboard more often. This increased engagement with the QMCU. Therefore mobile interface of QMCU motivated students to access the QMCU dashboard more frequently which is meant to help students to understand more about their performance compared to class performance.
- The mobile dashboard of QMCU allowed students to take a quiz right after class and to receive immediate detailed feedback. Also, the mobile application supported timely access. As observers, we noticed that portability of the dashboard allowed students to discuss their results anytime and anywhere with friends and instructors.

\section{CONCLUSION}

The immediacy of feedback is the common feature of both Learning Analytics (LA) and Formative Assessment (FA). FA helps students to evaluate their early-stage understanding, whereas LA techniques provide students with sufficient feedback about their individual performance as well as increases their awareness about comparative student performance. Learner mobility should be considered when seeking to increase feedback speed.

The customized mobile dashboard allowed students to access their Quiz My Class Understanding (QMCU) dashboard whenever they wished. This helped to increase use of the QMCU application; students became engaged. Therefore, the customized mobile dashboard of QMCU was a 'success factor' encouraging students to use the application often. This was one of our principal objectives as frequent use focuses students on performance.

Future work will investigate wider applications of Mobile Learning Analytics (MLA). This will involve deeper quantitative and qualitative approaches to explore differences in performance between students who access the analytical dashboard using mobile and non-mobile devices. To further explore the potential of MLA, new analytical features will be added to QMCU's dashboard by obtaining data about students from the Blackboard system.

\section{REFERENCES}

[1] T. M. Davis and P. H. Murrell, Turning Teaching into Learning. The Role of Student Responsibility in the Collegiate Experience. ASHE-ERIC Higher Education Report No. 8: ERIC, 1993.

[2] LAK, in 1st International Conference on Learning Analytics and Knowledge, Banff, Alberta

February 27-March 1, 2011.

[3] L. Johnson, R. Smith, H. Willis, A. Levine, and K. Haywood, "The 2011 horizon report," The New Media Consortium, Austin, Texas, 2011.

[4] G. Siemens and R. S. d. Baker, "Learning analytics and educational data mining: towards communication and collaboration," in Proceedings of the 2nd International Conference on Learning Analytics and Knowledge, 2012, pp. 252-254.

[5] George Siemens and Phil Long. (2011, 08-06). Penetrating the Fog: Analytics in Learning and Education. Available: http://www.educause.edu/EDUCAUSE+Review/EDUCAUSEReviewM agazine Volume46/PenetratingtheFogAnalyticsinLe/235017

[6] M. Booth. (2012). Learning Analytics: The new Black. Available: http://www.educause.edu/ero/article/learning-analytics-new-black

[7] E. Kosba, V. Dimitrova, and R. Boyle, "Using Student and Group Models to Support Teachers in Web-Based Distance Education," in User Modeling 2005. vol. 3538, L. Ardissono, P. Brna, and A. Mitrovic, Eds., ed: Springer Berlin Heidelberg, 2005, pp. 124-133.

[8] L. Ali, M. Hatala, D. Gašević, and J. Jovanović, "A qualitative evaluation of evolution of a learning analytics tool," Computers \& Education, vol. 58, pp. 470-489, 2012.

[9] V. Podgorelec and S. Kuhar, "Taking Advantage of Education Data: Advanced Data Analysis and Reporting in Virtual Learning 
Environments," Virtualiose mokymo terpèse esančių duomenu analizavimo ir pateikimo galimybių svarba studijų procese., pp. 111-116, 2011.

[10] K. Verbert, E. Duval, J. Klerkx, S. Govaerts, and J. L. Santos, "Learning Analytics Dashboard Applications," American Behavioral Scientist, 2013.

[11] N. Aljohani, S. Loke, and W. Ng, "A Mobile-Based Group Quiz System to Promote Collaborative Learning and Facilitate Instant Feedback," presented at the 9th World Conference on Mobile and Contextual Learning: mLearn 2010, Malta, 2010.

[12] G. J. Hwang and H. F. Chang, "A formative assessment-based mobile learning approach to improving the learning attitudes and achievements of students," Computers \& Education, vol. 56, pp. 1023-1031, 2011.

[13] N. R. Aljohani and H. C. Davis, "Significance of Learning Analytics in Enhancing the Mobile and Pervasive Learning Environments," in Next Generation Mobile Applications, Services and Technologies (NGMAST), 2012 6th International Conference on, 2012, pp. 70-74.

[14] M. Heritage, "Formative assessment and next-generation assessment systems: Are we losing an opportunity," Washington DC: Council of Chief State School Officers, 2010.
[15] D. R. Sadler, "Formative assessment and the design of instructional systems," Instructional science, vol. 18, pp. 119-144, 1989.

[16] P. Black and D. Wiliam, "Assessment and classroom learning," Assessment in education, vol. 5, pp. 7-74, 1998.

[17] D. Nicol and D. Macfarlane-Dick, "Rethinking formative assessment in HE: a theoretical model and seven principles of good feedback practice," The Higher Education Academy, 2004.

[18] R. M. Gagne, "The conditions of learning," 1970.

[19] G. Gibbs and C. Simpson, "Conditions under which assessment supports students' learning," Learning and teaching in higher education, vol. 1, pp. 3-31, 2004.

[20] L. W. Anderson, D. R. Krathwohl, and B. S. Bloom, A taxonomy for learning, teaching, and assessing: Longman, 2005.

[21] A. Field, Discovering statistics using IBM SPSS statistics: Sage, 2013. 